\title{
BOUNDS OF THE PERIMETER OF AN ELLIPSE USING
}

\section{ARITHMETIC, GEOMETRIC AND HARMONIC MEANS}

\section{Miao-Kun Wang, Yu-Ming Chu, Yue-Ping Jiang And Song-Liang QiU}

Abstract. In this paper, we present several bounds for the perimeter of an ellipse in terms of arithmetic, geometric, and harmonic means, which improve some known results.

Mathematics subject classification (2010): 41A10, 33E05, 33C05, 26E60.

Keywords and phrases: Perimeter of an ellipse, arithmetic mean, geometric mean, harmonic mean, Toader mean.

\section{REFERENCES}

[1] M. Abramowitz And I. A. Stegun, EDS., Handbook of Mathematical Functions with Formulas, Graphs and Mathematical Tables, Dover, New York, 1992.

[2] G. Almkvist And B. Berndt, Gauss, Landen, Ramanujan, the arithmetic-geometric mean, ellipse, $\pi$, and the Ladies Diary, Amer. Math. Monthly 95 (1988), 585-608.

[3] H. Alzer AND S.-L. QIU, Monotonicity theorems and inequalities for the complete elliptic integrals, J. Comput. Appl. Math. 172 (2004), 289-312.

[4] G. D. Anderson, S.-L. Qiu, M. K. Vamanamurthy and M. Vuorinen, Generalized elliptic integrals and modular equations, Pacific J. Math. 192 (2000), 1-37.

[5] G. D. Anderson, M. K. Vamanamurthy and M. Vuorinen, Conformal Invariants, Inequalities, and Quasiconformal Maps, John Wiley \& Sons, New York, 1997.

[6] R. W. BARNARd, K. PEARCE AND K. C. RiChaRds, An inequality involving the generalized hypergeometric function and the arc length of an ellipse, SIAM J. Math. Anal. 31 (2000), 693-699.

[7] R. W. BARNARD, K. PeARCE AND K. C. Richards, A monotonicity property involving ${ }_{3} F_{2}$ and comparisons of the classical approximations of elliptical arc length, SIAM J. Math. Anal. 32 (2000), 403-419.

[8] R. W. Barnard, K. Pearce And L. Schovanec, Inequalities for the perimeter of an ellipse, J. Math. Anal. Appl. 260 (2001), 295-306.

[9] B. C. BERndT, Ramanujan's Notebooks, Part III, Springer-Verlag, New York, 1991.

[10] J. M. Borwein And P. B. Borwein, Pi and the AGM, John Wiley \& Sons, New York, 1987.

[11] B. C. CARLson, Special Functions of Applied Mathematics, Academic Press, New York, 1977.

[12] T. R. Chandrupatla And T. J. Osler, The perimeter of an ellipse, Math. Sci. 35 (2010), 122-131.

[13] C.-P. Chen And F. QI, The best bounds in Wallis' inequality, Proc. Amer. Math. Soc. 133 (2005), 397-401.

[14] Y.-M. CHU AND M.-K. WANG, Optimal Lehmer mean bounds for the Toader mean, Result. Math., 61 (2012), 223-229.

[15] S. Ponnus Amy AND M. Vuorinen, Univalence and convexity properties of Gaussian hypergeometric functions, Rocky Mountain J. Math. 31 (2001), 327-353.

[16] S.-L. QIU AND M. Vuorinen, Special functions in geometric function theory, in: Handbook of Complex Analysis: Geometric Function Theory, Vol. 2, Elsevier Sci. B. V., Amsterdam, 2005, pp. 621-659.

[17] E. D. RainVille, Special Functions, MacMillan, New York, 1960.

[18] GH. ToAder, Some mean values related to the arithmetic-geometric mean, J. Math. Anal. Appl. 218 (1998), 358-368. 
[19] M. VuORInEN, Hypergeometric functions in geometric function theory, Special functions and differential equations (Madras, 1997), 119-126, Allied Publ., New Delhi, 1998.

[20] E. T. Whittaker And G. N. Watson, A Course of Modern Analysis, 4th ed., Cambridge Univ. Press, New York, 1962. 